\title{
Comparison of North American Seismic Screening Methods Applied to School Buildings
}

\author{
Helene Tischer, Denis Mitchell and Ghyslaine McClure \\ Department of Civil Engineering and Applied Mechanics, McGill University, Montréal QC H3A 0C3, Canada
}

\begin{abstract}
An ongoing project at McGill University is aimed at developing an adapted seismic screening method for schools in the province of Québec, Canada. As part of this project the "FEMA154 Rapid Visual Screening of Buildings for Potential Seismic Hazard" and the "NRC92 Manual for Screening of Buildings for Seismic Investigation" were used to assess 102 school buildings located in the city of Montréal. Results for both methods are in reasonable agreement, with $65 \%$ of the buildings requiring a detailed evaluation according to FEMA154 and 50\% according to NRC92. Findings highlighted the particular characteristics of educational facilities: they are low rise buildings with high incidence of structural irregularities. Accounting for them in the screening phase is essential, and is better achieved by NRC92. However, this method is largely based on expert opinion, which makes it difficult to update, while FEMA154 uses a rational methodology for calculating vulnerability scores based on the capacity spectrum approach. The FEMA154 analytical procedure allows updating and adapting the method to its use outside its intended scope.
\end{abstract}

Key words: Seismic screening methods, vulnerability, schools.

\section{Introduction}

Schools deserve special attention regarding earthquake performance because of their unique occupancy and important post-earthquake role. However experience in the past has demonstrated that they are especially vulnerable. This was illustrated by the effects of the 1997 Cariaco earthquake in Venezuela, where two out of five collapsed buildings were schools, and more than half the casualties were students and school personnel [1]. There have been many other examples that have demonstrated that school buildings are especially vulnerable to damage in moderate to strong earthquakes [2, 3]. Different reasons have been proposed to explain the observed poor performance, including the age of school buildings and that their complex structural features compromise seismic safety [4].

The protection of children is paramount in society because they provide for future generations and

Corresponding author: Helene Tischer, $\mathrm{PhD}$, research fields: seismic vulnerability assessment and retrofit of buildings, modal analysis. E-mail: helene.tischer@mail.mcgill.ca. represent an especially vulnerable segment of society. It has also been argued that safe schools must be considered a basic right in countries where school attendance is obligatory [5]. In addition, school buildings play a key role in restoring the normal functioning of society after an earthquake: they can be used as emergency shelters and their operation permits parents to return to work. In 2005, the OECD (Organization for Economic Co-operation and Development) acknowledging these facts, published recommendations on the earthquake safety of schools [6]. In this document, OECD suggests that "Member countries take steps to establish and implement programs of school seismic safety".

Seismic screening methods for school buildings are needed as the first phase in vulnerability assessment projects. One example of the successful application of the technique is the evaluation of all schools located in zones with high seismicity in the province of British Columbia, Canada. This study, conducted in 2004, indicated that $82 \%$ of the more than 850 schools evaluated were at moderate or high risk [7]. As a response to this study, the $\mathrm{BC}$ Ministry of Education 
committed 1.5 billion dollars to identify and retrofit the most at risk schools by 2020 .

The state of Oregon, United States, has also undertaken the screening of its essential facilities, including most of its K-12 public schools and community colleges. A total of 1,101 schools and 179 colleges were evaluated using the FEMA154 screening tool, representing more than 2,300 buildings. Results were made public in 2007 through the web [8]. For the evaluation the state was classified in three seismic zones, moderate, high and very high near the coast. Scores assigned for the high and very high regions were the same, with calculations considering a median short period spectral acceleration response value of $1.23 \mathrm{~g}$ and a median one second spectral acceleration response value of $0.45 \mathrm{~g}$. It was found that $31 \%$ of the educational facilities evaluated have a low, 22\% a moderate, $35 \%$ a high and $12 \%$ a very high collapse potential in a design-level earthquake. Some initial steps to reduce the seismic risk of essential facilities have already been taken. In 2009, an initial sum of 15 million US dollars was allocated to the seismic retrofit of public school buildings through the seismic rehabilitation grant program. The seismic mitigation work at high-occupancy schools is programmed to be completed by 2032 .

\section{Seismic Screening Methods}

Seismic screening methods, more specifically rapid visual screening or score assignment procedures, are intended to be coarse screening procedures using little resources per building. This is achieved by evaluating a limited number of features that influence seismic performance and assigning an overall score to each building. An ideal screening method will identify all those buildings that are potentially seismically hazardous, while limiting the number of buildings that will pass a more detailed evaluation [9].

Seismic screening methods can be classified as observed or predicted vulnerability procedures, or hybrid methods, depending on the type of source information used. Observed vulnerability procedures use statistics of damages in past earthquakes, sometimes combined with expert opinion, to determine the probable behavior of structures under future seismic events. The main setback of this approach is the possible insufficiency of observational data, as is the case in Canada, and the subjectivity in judging data. The method also lacks analytical justification. Predicted vulnerability methods try to overcome these shortages by using analytical procedures to determine the probable behavior of a structure subjected to a design-level earthquake loading. The limitation of this approach is the time and computational effort required by detailed analysis. Therefore a balance between effort and precision has to be found [10].

The first comprehensive rapid visual screening method was developed in the United States in the late 1980s by the Applied Technology Council under contract to the Federal Emergency Management Agency $[11,12]$. The work was mainly motivated by the advances in design codes that made it possible to design relatively safe new buildings. This method, published as the FEMA154 report - Rapid Visual Screening of Buildings for Potential Seismic Hazard — is probably the most widespread screening tool, and there is considerable guidance on its application [13, 14]. The method has also served as a prototype for the development of screening tools in other countries, as for example in Switzerland [15] and Italy [16]. The current Canadian seismic screening method - Manual for Screening of Buildings for Seismic Investigation (NRC92) [17], is also largely based on the first edition of FEMA154. There are other efficient methods, developed independently, such as the procedure of the New Zealand Society for Earthquake Engineering [9]. This method judges existing buildings by comparing them to current New Zealand standards. Another example is the Japanese Seismic Index Method, a multiphase screening procedure that estimates the vulnerability of an existing building by a seismic performance index calculated for every story in each 
main direction and based on key characteristics of the building. This method has been used to evaluate lowand mid-rise reinforced concrete buildings in Japan since 1975 [18].

For the present research FEMA154 and NCR92 were evaluated. A more detailed description of the two methods follows.

\subsection{FEMA154}

FEMA154 was first published in 1988 [19, 20], but was significantly improved in 2002 with the release of its second edition. The screening is done by visual observation of the building, and can be completed by means of a sidewalk survey, although entering the building and consulting existing plans and other documentation is recommended. Based on this inspection a data collection form is completed. Initially the lateral load resisting system has to be identified and related to one of the 15 predefined building types. A basic structural hazard score is provided for each building type. To consider specific characteristics of the building that could affect its seismic performance, the score is then altered by adding or subtracting score modifiers to obtain the final structural score. Score modifiers related to building height, vertical and horizontal irregularities, year of construction and soil type are provided. Higher final structural scores correspond to a better seismic performance, and usually they range from 0 to around 6 . It is recommended that buildings with a score of 2 or less should be evaluated in more detail.

In the first edition the basic structural hazard scores were calculated as the negative of the logarithm (base10) of the probability of damage $(D)$ exceeding $60 \%$ of the building value, given a ground motion represented by the NEHRP effective peak acceleration, as shown in Eq. (1).

$$
B S H=-\log _{10}[P(D \geq 60 \%)]
$$

To determine the probability of occurrence of different levels of damage given a specified ground motion, expert opinion was used (ATC-13 report [21]).
This ATC report was concerned exclusively with buildings constructed according to Californian building practices, and again expert opinion was sought out to make the results applicable to other regions of different seismicity. The score modifiers were also calculated based on expert criteria.

For the second edition of FEMA154 a more rational approach is implemented. The $B S H$ (basic structural hazard score) for each building type is defined as the negative of the logarithm (base 10) of the probability of collapse $(P)$ of the building, given a ground motion corresponding to the $M C E$ (maximum considered earthquake), as shown in Eq. (2).

$$
B S H=-\log _{10}[P(\text { collapse given } M C E)]
$$

The probability of collapse is the probability of the building being in complete damage state times the fraction of the buildings in complete damage state that collapse.

To determine the probability of being in complete damage state first the spectral displacement is calculated using a nonlinear static analysis procedure using the capacity spectrum method [22], depicted in Fig. 1a. This method is based on the assumption that the maximum inelastic deformation of a nonlinear single degree of freedom system can be estimated from the maximum elastic deformation of a linear elastic single degree of freedom system which has natural period and damping values higher than the original nonlinear one. The inputs of the method are the lateral force-deformation relationship of the structure, commonly known as push-over curve, and the seismic load demand. Both are plotted in accelerationdisplacement response spectrum format. In this format periods can be represented by radial lines, and the equivalent period is assumed to be the secant period at the intersection of the capacity spectrum and the seismic demand spectrum reduced for equivalent damping. The equivalent damping is estimated based on the area under the capacity curve. Since both equivalent period and damping are dependent on the 
a. Capacity spectrum method

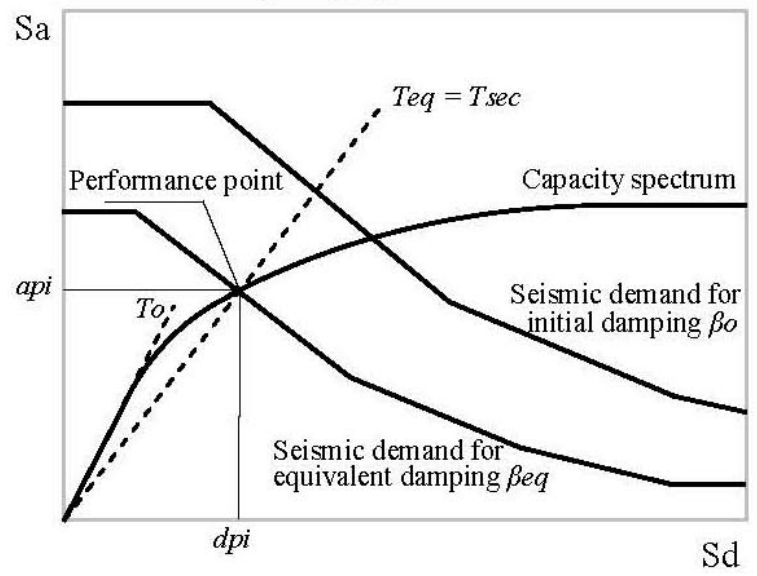

b. Fragility curves

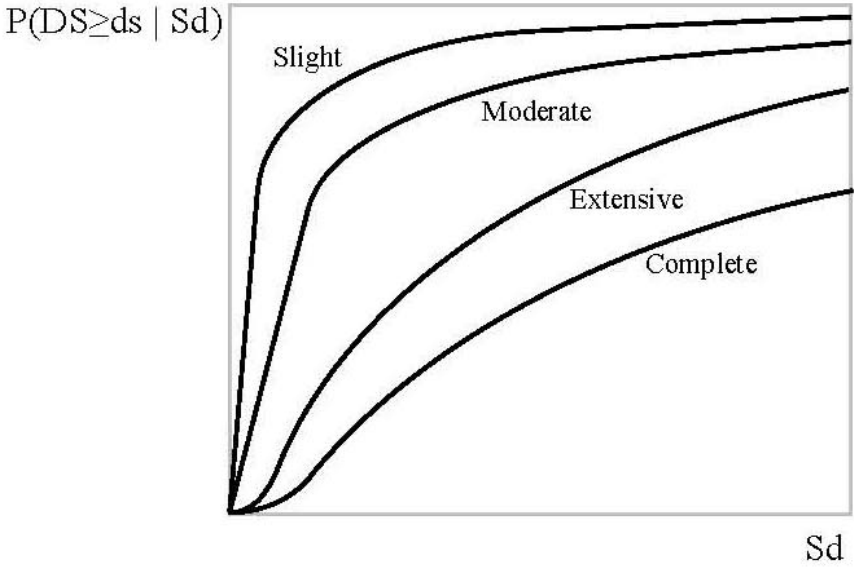

Fig. 1 Estimation of the probability of complete damage state of a building class [13].

estimated maximum spectral displacement, an iterative process is followed for its calculation.

The estimated spectral displacement is used to determine the probability of complete damage state from a fragility curve corresponding to the building type, as can be seen in Fig. 1b. This probability is multiplied by the fraction of buildings that will collapse if they reach their complete damage state, to obtain the probability of collapse and calculate the basic structural hazard scores. A similar procedure is used to calculate the score modifiers.

\section{$2.2 N R C 92$}

The NRC92 procedure was developed in Canada in 1992. Largely based on the first edition of FEMA154, the practical implementation of NRC92 relies on a data collection form that can be filled out by visual inspection of the building. It is expected that the exterior as well as the interior are evaluated, and recommended that building plans are considered. The user first has to identify the lateral load resisting system and correlate it to 15 different building types, very similar to those of FEMA154. High importance is given to the identification of building irregularities, differentiating between seven different types. Non-structural hazards also have to be identified.

A structural index is computed by multiplying five factors related to local seismicity, soil conditions, lateral load resisting system, vertical and horizontal irregularities and building importance. A non-structural index is also computed, based on the observed non-structural hazards, the soil conditions and building importance. The final score, called the SPI (seismic priority index), is the sum of a structural index and a non-structural index. In contrast to FEMA154, a high final score indicates high priority for refined seismic vulnerability analysis of the building. It is suggested that buildings with a score less than 10 be treated as low priority, 10 to 20 as moderate priority, 20 to 30 as high priority and more than 30 as potentially hazardous requiring immediate attention.

Although in the NRC92 guidelines it is stated that the method is largely based on the first edition of FEMA154, specific details on how the method was adapted for Canadian seismicity and building practice are not provided. However, it is clear that score calculations are mainly based on engineering expert opinion. The seismicity, soil, type of structure and irregularities factors were all obtained by comparing code requirements of different editions of the NBC (National Building Code of Canada).

\section{Schools in Québec}

This study was conducted in the province of Québec, Canada, considered a moderate seismic zone. Most of the population is located in the St. Lawrence River 
valley, the province's most active seismic zone. The Charlevoix region has the highest seismicity. According to 2010 NBC Uniform Hazard Spectral values assigned to LaMalbaie are $S_{a}(0.2 \mathrm{~s})=2.30 \mathrm{~g}$ for short periods and $S_{a}(1.0 \mathrm{~s})=0.52 \mathrm{~g}$ for long periods, with a probability of exceedence of $2 \%$ in 50 years. However, this is a rather confined zone of about $60 \mathrm{~km}$ in radius. More typical values are those of the two largest cities of the province, Montréal with $S_{a}(0.2 \mathrm{~s})=$ $0.64 \mathrm{~g}$ and $S_{a}(1.0 \mathrm{~s})=0.14 \mathrm{~g}$, and Québec City, with $S_{a}$ $(0.2 \mathrm{~s})=0.55 \mathrm{~g}$ and $S_{a}(1.0 \mathrm{~s})=0.15 \mathrm{~g}$. These two cities account for half of the province's population.

In Québec moderate and strong earthquakes have occurred in the past, and they will most certainly occur in the future. The large events have a relatively long return period (several centuries) and hence the general population has the impression that earthquakes are not likely in the region. Although Québec's earthquakes in the past have not caused loss of human life, extensive property damage has been reported. Some examples are the 1935 Timiskaming earthquake (magnitude 6.1 $M_{w}$ ) and most recently the 1988 Saguenay earthquake (magnitude $5.9 M_{w}$ ) [23].

Since experience with strong earthquakes is limited in Eastern Canada, reported seismic damage to schools has been mostly to non-structural elements in connection with moderate earthquakes. There was considerable damage reported to one Collegiate and Vocational School in Cornwall after the 1944 Cornwall-Massena earthquake [23]. The 1988 Saguenay earthquake produced architectural damage to 33 out of 42 public schools of the two most affected communities [24]. The site visit team also drew attention to the dangers of unreinforced masonry infill walls, and warned about the abundance of them particularly in schools and hospitals [25].

A school inventory report from the Québec Ministry of Education [26] has classified all the provincial public school buildings into five main structural/architectural categories and determined their general seismic vulnerability features relating the structural type to the construction year. The five categories and their province-wide occurrence are presented in Fig. 2, totaling approximately 3,600 schools. No distinction between different buildings at each location was made. It is noteworthy that around $80 \%$ of all public schools were constructed prior to the introduction of modern earthquake-resistant design code provisions in Canada, i.e., after 1970. This inventory was a first step in the vulnerability assessment of schools in Québec and its results highlighted the need for more detailed studies. Clearly, a detailed school-by-school evaluation is not feasible on a large scale and the development of a screening method adapted to address the specific characteristics of the school building inventory is necessary.

\section{Evaluation of School Buildings}

The goal of this research is to develop such an adapted seismic screening method for school buildings of the province of Québec. As part of the study the seismic vulnerability of 16 high schools (secondary education level) comprising a total of 102 individual buildings was studied. These schools are designated as post-critical shelters on the island of Montréal, mostly based on their location and their capacity to shelter a large number of disaster victims. A detailed database of the characteristics of the school buildings was created. Information from plans, site visits and the city's seismic microzonation map [27] was used.

It was found that most school buildings are low rise: over $3 / 4$ of them are three stories high or less, with the tallest being six stories high. The floor area varies

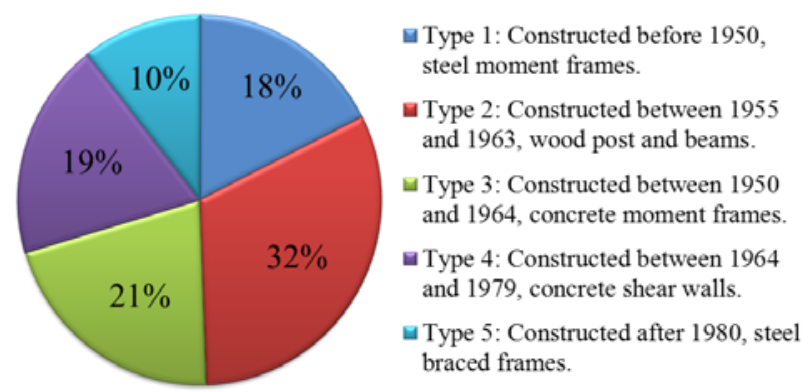

Fig. 2 Initial classification of school buildings in Québec [26]. 
between 200 and $5,300 \mathrm{~m}^{2}$, with an average value of $2,000 \mathrm{~m}^{2}$. It is noted that $87 \%$ of the structures were built in the 1960s and 1970s. The most common lateral load resisting systems, which account for $80 \%$ of the studied buildings, are: concrete frames with infill masonry shear walls, concrete shear walls and steel moment frames. As expected the evaluated schools are complex structures, with features that could potentially affect their seismic behavior. Buildings with re-entrant corners, steps in elevation, potential for pounding, exterior cladding and heavy partition walls are common. Table 1 summarizes the most common features and their percentage of occurrence. Besides, four of the 16 school campuses are located on soils prone to ground motion amplification.

Preliminary assessments using the FEMA154 and NRC92 seismic screening procedures were performed and cut-off scores were used as recommended for each method. Results of FEMA154 suggested that $65 \%$ of the buildings should undergo a detailed evaluation. NRC92 results were similar, finding $12 \%$ of the buildings with low priority for further assessment, 38\% moderate priority, $34 \%$ high priority and $16 \%$ potentially hazardous. There is relatively good agreement in the results obtained with the two methods given that $80 \%$ of the buildings that did not comply with the screening of FEMA154 were classified as having high priority of intervention or being potentially hazardous by NRC92. The large proportion of buildings requiring detailed evaluation (65\% according to FEMA and $50 \%$ according to NRC92) appears somewhat alarmist for a moderate seismicity environment and provides further motivation for the development of better adapted screening methods that can identify more precisely the installations that need detailed seismic vulnerability assessment.

A companion study evaluated the seismic risk of operational and functional components of fourteen of the sixteen schools [28], according to the procedure in CAN/CSA S832-06 standards, "Seismic risk reduction
Table 1 Features that could affect seismic performance and their occurrence in evaluated schools buildings.

\begin{tabular}{ll}
\hline Feature & $\%$ of Buildings \\
\hline Irregular building plan & $40 \%$ \\
Steps in elevation view & $40 \%$ \\
Heavy unreinforced masonry partition walls & $90 \%$ \\
Potential for pounding & $99 \%$ \\
Exterior cladding & $80 \%$ \\
Material deterioration & $35 \%$ \\
\hline
\end{tabular}

of OFCs (operational and functional components) of buildings" [29]. Around 450 typical components were evaluated in total, from which $20 \%$ were rated high and $54 \%$ moderate risk. The most common problem identified was lack of restraint of the non-structural components.

\section{Advantages and Shortcomings of Each Method}

\subsection{Procedures behind Score Calculations}

Supporting documentation for NRC92 is limited and this creates challenges for any attempt of updating the procedure. An update of NRC92 is needed because it was largely based on the first edition of FEMA154, which has been thoroughly revised. On the other hand, FEMA154 uses a more sound methodology for calculating the vulnerability scores than NRC92, with the calculations based on the capacity spectrum method as described in ATC-40 [22]. However the application of ATC-40 has raised concerns in the past, compared with other simplified analysis methods with poor agreement. Furthermore, when comparing to results of response history analysis, significant differences could be found [30]. Some studies demonstrated that the estimated maximum deformations can be underestimated by as much as $50 \%$ [31]. Recognizing this concern, in 2004 a thorough evaluation of the existing method was conducted and an updated procedure was published in the FEMA440 report [32]. In this evaluation it was found that for short-period structures, with period less than $0.5 \mathrm{~s}$ approximately, the peak displacements are largely overestimated; this period range is typical of school buildings. For higher 
periods the ATC-40 methodology can either overestimate or underestimate the displacements, depending on the assumed hysteretic behavior of the evaluated building. The main modification of the method was the update of the expressions for the calculation of the equivalent or effective period $\left(T_{\text {eff }}\right)$ and damping $\left(\beta_{e f f}\right)$. Approximate equations, that are independent of the hysteretic curve and post-elastic stiffness ratio of the capacity curve used, are repeated in the Eqs. (3) to (5), were $\mu$ is the ductility demand, $T_{0}$ and $\beta_{0}$ are the initial period and elastic damping ratio for the nonlinear system, respectively.

$$
\text { For } \begin{aligned}
1.0<\mu & <4.0, \\
\beta_{e f f} & =4.9(\mu-1)^{2}+1.1(\mu-1)^{3}+\beta_{0} \\
T_{\text {eff }} & =\left[0.20(\mu-1)^{2}-0.038(\mu-1)^{3}+1\right] T_{0}
\end{aligned}
$$

for $4.0 \leq \mu<6.4$,

$$
\begin{aligned}
& \beta_{\text {eff }}=14.0+0.32(\mu-1)+\beta_{0} \\
& T_{e f f}=[0.28+0 . .13(\mu-1)+1] T_{0}
\end{aligned}
$$

for $\mu>6.5$,

$$
\begin{aligned}
& \beta_{\text {eff }}=19\left[\frac{0.64(\mu-1)-1}{[0.64(\mu-1)]^{2}}\right]\left(\frac{T_{\text {eff }}}{T_{0}}\right)^{2}+\beta_{0} \\
& T_{\text {eff }}=\left\{0.89\left[\sqrt{\frac{(\mu-1)}{1+0.05(\mu-2)}}-1\right]+1\right\} T_{0}
\end{aligned}
$$

Based on these equations, scores for FEMA154 were recalculated in the present study. Fig. 3 shows a comparison between the basic structural hazard scores presented in FEMA154 and the updated values. On

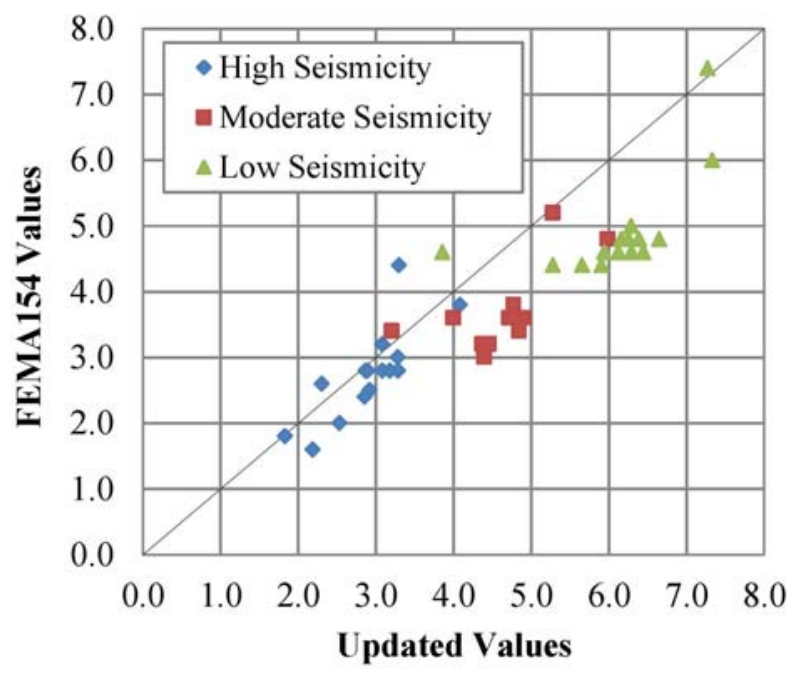

Fig. 3 Comparison between the basic structural hazard scores of FEMA154 and calculated values from the updated capacity spectrum method. average the values increased $14 \%$ for high seismicity, $29 \%$ for moderate seismicity and $28 \%$ for low seismicity. Increased values are related to a better earthquake performance. This result was expected, since the basic structural hazard scores are calculated for low rise buildings with relatively short periods, and the capacity spectrum method as presented in ATC-40 tends to overestimate the predicted maximum displacement values for short periods.

\subsection{Spectral Response Acceleration Values}

FEMA154 targets seismicity of the United States. Three seismicity regions (high, moderate and low) are defined based on design spectral acceleration values for periods of 0.2 and 1.0 seconds, $S(0.2 \mathrm{~s})$ and $S(1.0 \mathrm{~s})$. Limiting values were taken from FEMA310 [33], ignoring local site effects. To determine the median spectral acceleration response values for each seismic region first each county was classified based on the maximum $S(0.2 \mathrm{~s})$ and $S(1.0 \mathrm{~s})$ values. The median of these maximum values was calculated for each region and used for the score calculations. The median values and the basic structural hazard scores and modifiers were recalculated [34] considering the seismicity of Québec's cities and towns as specified in the 2005 edition of the NBC [35], considering the same spectral acceleration limits for the three seismicity regions.

Although the spectral accelerations in Canada and the United States are calculated with the same hazard level, i.e., a probability of exceedance of $2 \%$ in 50 years, there are differences in the calculations that account for cross-border inconsistencies, as for example the use of the median seismicity values in Canada versus the mean values in the United States. Furthermore, when using FEMA154 in Canada, one important consideration to be addressed is that in the United States the spectrum is reduced by $2 / 3$ for building design [36], while this reduction is not used in Canada. This has an impact on the calculated scores, and the use of the same spectral acceleration limits to define the three seismicity regions is questionable, 
since these limits were prescribed considering the reduction factor. When analyzing the case of the city of Montréal for example, a city identified as having moderate seismicity as per NBC $(S(0.2 \mathrm{~s})=0.69 \mathrm{~g}$ and $S(1.0 \mathrm{~s})=0.14 \mathrm{~g}$ for Site Class C), it would be classified by FEMA154 as moderate seismicity if applying the $2 / 3$ reduction factor and high seismicity if not.

NRC92, although conceived for the Canadian context, has yet to be updated to consider the revised uniform seismic hazard data which have been implemented in NBC 2010. The seismicity used by NRC92 is that specified in the 1990 NBC [37], with hazard maps developed in 1985. The effective seismic zone of the site of interest is calculated according to the peak ground acceleration and peak ground velocity with probability of being exceeded of $10 \%$ in 50 years. The new models developed for the 2005 NBC included the latest findings related to historical seismic events in Canada, new attenuation laws, a better description of the site conditions and the explicit consideration of uncertainty [38].

\subsection{Site Classification}

Design spectral accelerations are determined by the expected seismic excitation and local geotechnical conditions at the site. Both in the US and in Canada soil is classified into six seismic categories, from type A to $\mathrm{F}$, ranging from hard rock (Site Class A) to poor soil (Site Class F). For the classification of each type, the parameters used are the measured shear wave velocity or standard blow count. Ground motion amplification factors for short and long periods, $F_{a}$ and $F_{v}$, dependent on the expected intensity of shaking, are defined for each site class. For the US, the reference soil is type B, meaning that $F_{a}$ and $F_{v}$ values are equal to one for soil type B [39]. In the seismic provisions of the 2005 NBC, the American classification system was adopted with small changes. However the reference soil in Canada was defined as type $\mathrm{C}$ (defined as very dense soil and soft rock, with shear wave velocity between 360 and
$760 \mathrm{~m} / \mathrm{s}$ ), to be consistent with previous editions of the NBC [40]. Therefore $F_{a}$ and $F_{v}$ values for the same soil type are lower in Canada than in the US. This implies that when using FEMA154 with spectral acceleration values and soil definitions for Canada the site effects are overestimated.

The four different soil types considered by NRC 92 have foundation factors $F$, ranging from 1.0 to 2.0. These factors, based on design practice of the time, do not consider the differences between short and long period building responses and the influence of the intensity of shaking.

\subsection{Configuration Irregularities}

The findings of the initial evaluation reported in Section 4 indicated that schools are complex structures: it was found that $80 \%$ of the examined buildings have some type of irregularity, with almost $40 \%$ having at least one vertical and one plan irregularity. While FEMA154 only differentiates between vertical and plan irregularities, NRC92 identifies seven different types: vertical and horizontal irregularity (torsion), short concrete columns, soft story, pounding, major modifications and material deterioration. The effect of this refined classification can be appreciated when studying the influence of different irregularities that can be classified as vertical (e.g., steps in elevation view, building on a slope, soft story) on the score results. NRC 92 classified $40 \%$ of school buildings with only one vertical irregularity as high priority and $70 \%$ with two vertical irregularities as high priority. Using FEMA154 the percentage of buildings in need of a detailed assessment was $90 \%$ and $100 \%$, respectively for each case. This demonstrates that the NRC92 approach gives greater differentiation when more than one irregularity exists.

In FEMA154 score modifiers for vertical irregularities were based on engineering judgment. For high and moderate seismic zones, the modifiers were chosen so that if it were the only modifier considered, the final score would be below the cut-off score of two. 
For low seismicity, modifiers similar to those of the moderate seismic zone were adopted. For the calculation of the plan irregularity modifiers, an increase of $50 \%$ in the spectral acceleration response values was used. This approach seems appropriate when evaluating general building stock (including commercial and residential), where irregularities in plan and elevation should be rather uncommon. When evaluating school buildings however, due to the prevalence of configuration irregularities, a more discriminating evaluation is desirable. Finding a balance between the simplicity of the method and the detailed identification of irregularities is challenging. An example on how this can be achieved is found in the screening procedure of New Zealand [9]. Even in a first phase evaluation, four critical structural features have to be identified (plan and vertical irregularities, short columns and pounding potential) and the effect on the structural performance of each has to be classified as severe, significant or insignificant. Clear guidance on how to classify the severity is provided. For buildings with an L-shape plan, for example, the effect on structural performance is determined by comparing the length and the width of the wings.

\subsection{Potential for Pounding}

When insufficient or no separation is provided between adjacent buildings they will likely suffer from pounding during a strong earthquake. This will induce high amplitude impact loadings, and experience in past earthquakes has demonstrated that this problem can even cause buildings to collapse. During the 1985 Mexico City earthquake, $15 \%$ of building collapses could be attributed to these severe pounding effects [41].

While FEMA154 does not consider pounding, NRC92 incorporates it in calculating the score, and the limiting distance between buildings is defined in terms of the velocity-related seismic zone (dependent on the expected peak ground velocity) and number of stories. Since the 2005 edition of NBC stipulates the seismic demand in terms of spectral acceleration values only, other expressions have to be found to account for this effect.

Experience in past earthquakes has demonstrated that the effect of pounding is most critical for adjacent buildings with different heights, periods and masses. Floors at different elevations may result in the slabs of one building to impact columns of the other building generating shear failure and partial or total collapse. In absence of these adverse factors, pounding usually will only induce local damage [42]. Given the high incidence of potential for pounding in the evaluated schools, the identification of the probable severity of damages is important in the rapid visual screening phase.

\subsection{Non-structural Components}

Another important aspect considered by NRC92, while ignored by FEMA154, is the evaluation of seismic vulnerability and risk related to damage of operational and functional building components. Addressing such functionality issues is a cost-effective first step for retrofit and directly translates into increased public safety. Furthermore, if the installations are classified as post-critical, as is the case with school buildings designated as post-critical shelters, non-structural damage must be limited. In a moderate seismic zone non-structural damage can also be more widespread than structural damages or collapse, as has been demonstrated by experience in past earthquakes in Québec [25], where earthquakes have typically higher frequency content than in western North America.

The initial evaluation highlighted the extensive use of heavy partition walls in schools, many of them made of unreinforced masonry blocks (terra cotta or concrete). This is especially worrisome in school buildings with long corridors considering the potential life safety hazard that out-of-plane failure can cause. A detailed inventory of these walls can be made to better assess their vulnerability. Key characteristics for wall 
performance include thickness, height and effective lateral support. The wall density and location will furthermore help to prioritize the cases where corrective measures are necessary.

\subsection{Building Importance}

Schools fall into two distinct classes regarding importance: post-disaster shelters and ordinary schools which all belong to the post-critical building category according to NBC. The different performance objectives of these two occupancies should be acknowledged by the seismic screening method: school occupancy requires essentially safety performance while post-earthquake shelter occupancy requires a minimum of damage for nearly immediate occupancy and functionality after strong shaking. While ignored by FEMA154, NRC92 asks for the calculation of a building importance factor based on the occupancy and use of the building. For school buildings, the structural index is increased between $20 \%$ and $50 \%$, compared with a normal occupancy building. For post-disaster buildings which have to remain fully functional after the earthquake, the increase is between $50 \%$ and $100 \%$.

\subsection{Cut-off Scores}

While FEMA154 only suggests one cut-off score, classifying a building either as safe or as requiring a more in depth examination, NRC92 defines four distinct categories: low, moderate or high priority for future intervention or potentially hazardous. This more detailed classification gives a better sense of the hazard of each building and the need for a more detailed seismic evaluation.

The scores of FEMA154 are directly related to the probability of the building to collapse given the maximum considered earthquake. A score of one indicates a probability of collapse of 1 in 10 or $10 \%$, a score of two indicates a probability of $1 \%$ and a score of 3 indicates a probability of $0.1 \%$, etc. Based on these numbers a detailed ranking system is presented in Table 2, as used in the evaluation of schools and other critical public facilities in Oregon [8].
Table 2 Proposed ranking to be used with FEMA154 [8].

\begin{tabular}{lll}
\hline Classification & Probability of collapse & Score \\
\hline Very high & $100 \%$ & $\leq 0.0$ \\
High & $10 \%$ to $100 \%$ & $0.1-1.0$ \\
Moderate & $1 \%$ to $10 \%$ & $1.1-2.0$ \\
Low & below $1 \%$ & $>2.0$ \\
\hline
\end{tabular}

\section{Improved Screening Method}

As discussed in Section 2, the analytical procedure behind the score calculations of FEMA154 makes it possible to update and adapt the method to its use outside its intended scope, while NRC92 is difficult to modify as it is largely based on expert opinion. The rapid visual screening method under development therefore uses FEMA154 as a template, modifying it to serve the specific purpose of evaluating school buildings in Québec. Some key features of NRC92 are also incorporated.

The scores and modifiers are being recalculated according to Eq. (2), with spectral displacements estimated by the capacity spectrum method of FEMA440. The classification of lateral load resisting systems used is that of NRC92, analogous to FEMA154. For the 102 school buildings of the initial study, the seismicity is represented by Montréal's acceleration response spectrum and local site conditions are considered by using the corresponding Canadian ground motion amplification factors $F_{a}$ and $F_{v}$ specific to Montréal's seismicity.

Major changes will be introduced in the treatment of irregularities, adopting the NRC92 classification since it covers the findings of the initial evaluation of the schools. Furthermore, the effect of each type of irregularity on the seismic performance was classified as severe, significant or insignificant. The detrimental effect of the irregularities will be represented by increased spectral response acceleration values.

The evaluation of architectural components (partitions, cladding and exterior finishes) will be included, and the findings of the detailed survey of the unreinforced heavy partition walls will serve to define the appropriate screening mechanism. 


\section{Conclusions}

Having earthquake-resistant schools is of prime importance. Not only do schools have unique occupancy characteristics, but they play a key role in response and recovery efforts after a damaging earthquake. Unfortunately, school buildings tend to be especially vulnerable. In the province of Québec (eastern Canada) with regions of low and moderate seismicity, efforts are currently being made to assess the potential seismic performance of public school buildings. Seismic screening is appropriate as the first phase of a vulnerability assessment.

Two seismic screening methods are relevant when evaluating seismic vulnerability of buildings in Canada: NRC92, developed nationally and FEMA154, developed in the US, having similar construction and design practices. Both methods were used to evaluate 16 public school campuses comprising 102 buildings located in the city of Montréal. It is noteworthy that these schools are designated as emergency shelters by the city. School buildings are generally low-rise and have a limited number of types of lateral load resisting systems. Features that could adversely affect seismic performance are common. The high incidence of irregularities and the fact that many schools were constructed before modern seismic design codes were developed is in accordance with findings of similar studies in other countries, and could explain the large proportion of schools damaged in past earthquakes. According to the FEMA154 method, $65 \%$ of the buildings studied should undergo a detailed evaluation. With the NRC92 method, 34\% of the buildings were classified as having high priority for future intervention and $16 \%$ as potentially hazardous. Results of both evaluations are in reasonable agreement.

The methodologies employed for the score calculation of both screening methods are outdated. NRC92 is largely based on expert opinion and therefore difficult to update. On the contrary FEMA154, based on the capacity spectrum method, can be revised to include latest findings and seismic hazard updates. An average increase of $24 \%$ on the basic structural hazard scores was obtained when updating FEMA154, with higher scores indicative of a better performance. The clear analytical procedure behind FEMA154 also makes it possible to adapt the method for use in other countries.

The high incidence of irregularities $(80 \%$ for the evaluated schools) makes their detailed evaluation essential. FEMA154 groups the irregularities in two categories and quantifies their effect estimating the worst possible scenario. This not only fails to capture each building's specific characteristics, but also leads to over-conservative results. NRC92 partly overcomes these shortcomings by defining seven different types of irregularities.

\section{Acknowledgments}

This research was funded by the Natural Sciences and Engineering Research Council of Canada, through the Canadian Seismic Research Network (Strategic Networks Program). The authors wish to express their appreciation to the Centre de Securite Civile of the city of Montréal for their collaboration. This research was carried out with permission of the Ministère de l'Éducation, du Loisiret du Sport of the province of Québec. An early version of this paper was presented at the COMPDYN Conference in 2011 [43].

\section{References}

[1] O. A. López, J. J. Hernández, G. Del Re and J. Puig, Seismic risk in schools: The venezuelan project, in: OECD (Ed.), Proceedings of Keeping Schools Safe in Earthquakes, Ad Hoc Experts' Group Meeting on Earthquake Safety in Schools, Paris, Feb. 9-11, 2004, pp. 88-100.

[2] M. Dolce, Seismic safety of schools in Italy, in: OECD (Ed.), Proceedings of Keeping Schools Safe in Earthquakes, Ad Hoc Experts' Group Meeting on Earthquake Safety in Schools, Paris, Feb. 9-11, 2004, pp. 52-63.

[3] R. Spence, Strengthening school buildings to resist earthquakes: Progress in European countries, in: OECD (Ed.), Proceedings of Keeping Schools Safe in Earthquakes, Ad Hoc Experts' Group Meeting on 
Earthquake Safety in Schools, Paris, Feb. 9-11, 2004, pp. 217-228.

[4] ATC (Applied Technology Council), FEMA424 Design Guide for Improving School Safety in Earthquakes, Floods, and High Winds (1st ed.), ATC, Redwood, California, 2004.

[5] A. Chakos, Learning about seismic safety of schools from community experience in Berkeley, California, in: OECD (Ed.), Proceedings of Keeping Schools Safe in Earthquakes, Ad Hoc Experts' Group Meeting on Earthquake Safety in Schools, Paris, Feb. 9-11, 2004, pp. $45-51$.

[6] OECD (Organisation for Economic Co-operation and Development), OECD Recommendation Concerning Guidelines on Earthquake Safety in Schools, OECD, 2005.

[7] APEGBC (Association of Professional Engineers and Geoscientists of British Columbia) and Department of Civil Engineering of University of British Columbia, Bridging Guidelines for the Performance-Based Seismic Retrofit of British Columbia School Buildings (1st ed.), British Columbia Ministry of Education, Vancouver, 2005.

[8] V. S. McConnell, Statewide Seismic Needs Assessment: Implementation of Oregon 2005 Senate Bill 2 Relating to Public Safety, Earthquakes, and Seismic Rehabilitation of Public Buildings, State of Oregon, Department of Geology and Mineral Industries, 2007.

[9] New Zealand Society for Earthquake Engineering, Assessment and Improvement of the Structural Performance of Buildings in Earthquake, New Zealand Society for Earthquake Engineering, 2006.

[10] L. A. Mendes-Victor, C. S. Oliveira, J. Azevedo, A. Ribeiro, A. S. Elnashai and S. H. Jeong, Rapid Probabilistic Assessment of Structural Systems in Earthquake Regions, The 1755 Lisbon Earthquake: Revisited, Geotechnical, Geological, and Earthquake Engineering Series, Springer, Netherlands, 2009, pp. 335-349.

[11] ATC, FEMA154 Rapid Visual Screening of Buildings for Potential Seismic Hazard: A Handbook (2nd ed.), Applied Technology Council, Redwood, California, 2002.

[12] ATC, FEMA155 Rapid Visual Screening of Buildings for Potential Seismic Hazard: Supporting Documentation (2nd ed.), ATC, Redwood, California, 2002.

[13] G. C. Joshi and R. Kumar, Preliminary seismic vulnerability assessment of Mussoorie Town, Uttarakhand (India), Journal of Building Appraisal 5 (4) (2010) 357-368.

[14] R. B. Olshansky and Y. Wu, Evaluating earthquake safety in Mid-American communities, Natural Hazards Review 5 (2) (2004) 71-81.
[15] K. Lang, Seismic vulnerability of existing buildings, Ph.D. Thesis in Technical Sciences, Swiss Federal Institute of Technology, Zürich, 2002.

[16] E. Faccioli, V. Pessina, G. M. Calvi and B. Borzi, A study on damage scenarios for residential buildings in Catania city, Journal of Seismology 3 (3) (1999) 327-343.

[17] National Research Council Canada, Manual for Screening of Buildings for Seismic Investigation (1st ed.), National Research Council Canada, Ottawa, 1992.

[18] G. M. Calvi, R. Pinho, G. Magenes, J. J. Bommer, L. F. Restrepo-Vélez and H. Crowley, Development of seismic vulnerability assessment methodologies over the past 30 years, ISET Journal of Earthquake Technology 43 (3) (2006) 75-104.

[19] ATC, FEMA154 Rapid Visual Screening of Buildings for Potential Seismic Hazard: A Handbook (1st ed.), ATC, Redwood, California, 1988.

[20] ATC, FEMA155 Rapid Visual Screening of Buildings for Potential Seismic Hazard: Supporting Documentation (1st ed.), ATC, Redwood, California, 1988.

[21] ATC, ATC-13 Earthquake Damage Evaluation Data for California, 1st ed., ATC, Redwood, California, 1985.

[22] ATC, ATC-40 Seismic Evaluation and Retrofit of Concrete Buildings (1st ed.), ATC, Redwood, California, 1996.

[23] M. Bruneau and M. Lamontagne, Damage from 20th century earthquakes in eastern Canada and seismic vulnerability of unreinforced masonry buildings, Canadian Journal of Civil Engineering 21 (4) (1994) 643-662.

[24] R. Tinawi and D. Mitchell, 1988 Saguenay earthquake, damage to schools and post-disaster buildings, in: Proceedings of Engineering in our Environment: Annual Conference and 1st Biennial Environmental Speciality Conference, Hamilton, USA, 1990, pp. 573-590.

[25] D. Mitchell, R. Tinawi and T. Law, The 1988 Saguenay earthquake-A site visit report, Canadian National Comittee on Earthquake Engineering, 1989.

[26] D. Chagnon, School building stock/portrait of main characteristics for the study of the seismic resistance, Internal report, Ministère de l'Éducation, des Loisirs et du Sport, Direction générale du financement et de l'équipement, Direction de l'équipement scolaire, Québec, 2006. (in French)

[27] P. Rosset, M. Bour and L. Chouinard, Estimation of mean Vs30 maps and uncertainty for Montreal, Submitted to Earthquake Spectra, 2011.

[28] G. McClure, J. Cappai, R. Shapiro, M. Li, G. Dunlop-Brère and $P$. Keller, Assessing the post-earthquake functionality of critical buildings in Montreal, in: Proceedings of 9th U.S. National and 10th Canadian Conference on Earthquake Engineering, Toronto, Canada, 2010, Paper No. 993. 
[29] CSA (Canadian Standards Association), Seismic Risk Reduction of Operational and Functional Components (OFCs) of Buildings, CAN/CSA-S832-06, CSA, Rexdale, Ontario, 2006.

[30] S. D. Akkar and E. Miranda, Statistical evaluation of approximate methods for estimating deformation demands on existing structures, Journal of Structural Engineering 131 (1) (2005) 160-172.

[31] A. K. Chopra and R. K. Goel, Evaluation of NSP to estimate seismic deformation: SDF systems, Journal of Structural Engineering 126 (4) (2000) 482-489.

[32] ATC, FEMA440 Improvement of Nonlinear Static Seismic Analysis Procedures (1st ed.), ATC, Redwood, California, 2005.

[33] American Society of Civil Engineers, FEMA310 Handbook for the Seismic Evaluation of Buildings: A Prestandard (1st ed.), Federal Emergency Management Agency, Washington D.C., 1998.

[34] A. Karbassi and M. J. Nollet, Development of an index assignment procedure compatible with the regional seismicity in the province of Quebec for the rapid visual screening of existing buildings, Canadian Journal of Civil Engineering 35 (9) (2008) 925-937.

[35] National Research Council Canada, National building Code of Canada 2005, National Research Council, Ottawa, 2005.

[36] Building Seismic Safety Council, FEMA P-750 NEHRP Recommended Provisions for Seismic Regulations for New Buildings and Other Structures (7th ed.), Building Seismic Safety Council, Washington, D.C., 2009.
[37] National Research Council Canada, National building Code of Canada 1990, National Research Council, Ottawa, 1990.

[38] J. Adams and G. Atkinson, Development of seismic hazard maps for the proposed 2005 edition of the National Building Code of Canada, Canadian Journal of Civil Engineering 30 (2003) 255-271.

[39] Building Seismic Safety Council, FEMA302 NEHRP Recommended Provisions for Seismic Regulations for New Buildings and Other Structures, Building Seismic Safety Council, Washington, D.C., 1998.

[40] W. D. L. Finn and A. Wightman, Ground motion amplification factors for the proposed 2005 edition of the National Building Code of Canada, Canadian Journal of Civil Engineering 30 (2) (2003) 272-278.

[41] V. Jeng and W. L. Tzeng, Assessment of seismic pounding hazard for Taipei City, Engineering Structures 22 (5) (2000) 459-471.

[42] S. A. Anagnostopoulos, Building pounding re-examined: How serious a problem is it? in: Proceedings of 11th Word Conference on Earthquake Engineering, Acapulco, México, 1996, Paper No. 2108.

[43] H. Tischer, D. Mitchell and G. McClure, Comparison of seismic screening methods for schools in a moderate seismic zone, in: M. Papadrakakis, M. Fragiadakis, V. Plevris (Eds.), Proceedings of COMPDYN 2011, III ECCOMAS Thematic Conference on Computational Methods in Structural Dynamics and Earthquake Engineering, Paper No. 275, Corfu, Greece, 2011. 